\title{
EVOLUCIÓN Y CULTURA: UNA APROXIMACIÓN NATURALISTA A LAS CIENCIAS SOCIALES
}

\section{EVOLUTION AND CULTURE: A NATURALISTIC APPROACH TO SOCIAL SCIENCES}

\author{
Miguel Ángel CASTRO \\ Facultad de Ciencias Politicas y Sociología, \\ Departamento de Sociología I, UNED \\ Laureano CASTRO \\ Centro Asociado de Madrid, UNED \\ Miguel Ángel Toro \\ Departamento de Producción Animal, \\ ETS Ingenieros Agrónomos, Madrid
}

RESUMEN: Las tradiciones que configuran el cuerpo central de teoría en las ciencias sociales comparten la convicción de que las culturas constituyen sistemas que pueden ser interpretados sin tener en cuenta las características psicobiológicas de la naturaleza humana. Frente a esto, desde hace unos años, distintas aproximaciones naturalistas, como la psicología evolucionista y la teoría de la herencia dual, han logrado construir modelos bastante sólidos en el análisis de la cultura. Aquí se revisan brevemente los elementos básicos de esos modelos y, en la parte final del artículo, se presenta una propuesta alternativa basada en lo que denominamos el aprendizaje social asesor. logía.

PALABRAS ClAVE: Evolución, antropología, genética, socio- 
ABSTRACT: The traditions that form the central theoretical body of social sciences share the belief cultures constitute systems that can be interpreted ignoring the psychobiological characteristics of human nature. Opposing this, several naturalistic approaches, such as the evolutionary psychology and the dual inheritance theory, have managed, in the last years, to build models quite robust for the analysis of culture. Here, we review briefly the basic elements of these models and, at the end of the paper, an alternative proposal based in what we have called assessor social learning, is presented.

KEYWORDS: Evolution, anthropology, genetics, sociology.

\section{El proyecto darwinista de una ciencia de la naturaleza humana}

En 1871, doce años después de publicar On the Origin of Species by Means of Natural Selection, Darwin dirigió su atención a la explicación del comportamiento humano en su obra titulada The Descent of Man, and Selection in Relation to Sex. Trató de abordar en ella la complejidad de la conducta humana desde los principios establecidos en su teoría evolutiva. Aunque esta posibilidad venía ocupando al insigne biólogo desde el comienzo de sus reflexiones sobre la evolución, en $O n$ the Origin apenas había referencias al caso humano. Después de un largo proceso de maduración, Darwin se atrevió a publicar su minucioso estudio basado en un abundante conjunto de observaciones extraídas de la historia natural y la etnología. El propósito general de la obra era situar al hombre en su filum evolutivo, los primates, con los que nuestra especie mantenía innumerables afinidades morfológicas, anatómicas y fisiológicas, parentesco suficiente para establecer el vínculo evolutivo. Sin embargo, dentro del propio plan de la obra, no fue menos importante el esfuerzo realizado por Darwin para interpretar el comportamiento humano y animal desde la perspectiva de la selección natural. Dicho enfoque partía, de hecho, de la esencial continuidad entre las fuerzas y procesos responsables de la conducta animal y del comportamiento humano. En su The Descent of Man, Darwin sostenía la tesis de que el parentesco del hombre con los primates iba mucho más allá de los aspectos somáticos. 
Este punto de vista defendido por Darwin fue, además de lúcido, sumamente atrevido, hasta el punto de que la mayor parte de sus amigos del ámbito científico, defensores de las ideas evolucionistas, no compartían sus ideas sobre la evolución humana, optando por una posición mucho más comedida y conservadora. Por ejemplo A. R. Wallace, codescubridor de la evolución de las especies de acuerdo con el principio de selección natural, creía que las capacidades intelectuales y morales presentes en el hombre no eran el resultado de la evolución, sino de la voluntad del Creador, que las había puesto allí de acuerdo con sus designios. Wallace suponía que todos los seres humanos están dotados por naturaleza de las mismas capacidades y, sin embargo, consideraba como algo obvio que los seres humanos de comunidades primitivas sólo utilizaban una pequeña parte del potencial que poseía su cerebro y que, por tanto, no era verosímil que la evolución de esas capacidades en tan alto grado se hubiese producido por un proceso de selección natural. Su origen tenía que proceder de otra fuente, que no podía ser otra que la voluntad del Creador.

El punto de vista de Darwin resultaba más sutil, pues suponía que la existencia de órganos diseñados para ciertas funciones específicas por el proceso de selección natural era compatible con el hecho de que, en contextos ambientales específicos, algunos rasgos adaptativos cambiasen de función y, como resultado de un cierto bricolage, diesen lugar a curiosas utilidades, que en modo alguno pueden interpretarse como diseños intencionales ${ }^{1}$. Esta idea, sencilla como tantas otras aportaciones geniales, permitió a Darwin profundizar en el origen evolutivo de las capacidades intelectuales y morales del ser humano, defendiendo una tesis continuista.

Darwin sostuvo la idea de que tales capacidades habían surgido tras la aparición del lenguaje y del uso constante de todas sus facultades. Su tesis central fue que el comportamiento moral nació de la progresiva extensión de los instintos sociales a un círculo cada vez mayor de individuos. Los instintos sociales que promueven conductas favorables hacia un reducido número de individuos, próximos en grado de parentesco, se habrían ido extendiendo hacia otros individuos hasta hacerse permanentes en nuestra especie. Darwin añadía a esto la extraordinaria importancia que el individuo hace de la aprobación o censura de sus pró-

1 Por ejemplo, para Darwin los dispositivos de las orquídeas para atraer a los insectos no eran más que los órganos de cualquier otra flor debidamente ajustados. 
jimos y la elevada actividad de sus facultades mentales actuando sobre sus impresiones pasadas, de suerte que tal combinación de elementos, cultivados e incrementados por la acción, la educación, el ejemplo, la costumbre y la reflexión, permitían explicar el origen de su naturaleza moral. ¿Cuál pudo ser la causa, pues, de que las facultades morales del hombre hubieran sido seleccionadas a lo largo del proceso evolutivo? Darwin propuso a este respecto un argumento que podríamos considerar de selección de grupo. Consiste en suponer que aquellos grupos en los cuales se encontraban presentes individuos dotados con fuertes sentimientos de pertenencia, fidelidad, patriotismo y sacrificio debieron poseer una mayor eficacia biológica, frente a aquellos otros en los que esas sensibilidades no se presentaban o lo hacían en menor medida ${ }^{2}$.

Consciente de la importancia evolutiva de estos rasgos morales primitivos — primitivos en tanto que primordiales_- Darwin puso gran énfasis en señalar el peso extraordinario que debió tener la imitación, el hábito y la influencia del grupo a través de la aprobación y reprobación de la conducta propia y ajena. Darwin pensó que tales rasgos psicobiológicos y tales comportamientos sociales estaban presentes por igual en primitivos y civilizados, de suerte que la distancia que separaba a unos de otros debía de explicarse por una suerte de cambio — cultural y social- en el que la selección natural ocupaba un lugar secundario y en el que el peso del ambiente y la educación lo eran todo.

A pesar de la prudencia con la que Darwin se ocupo de estos temas, lo cierto es que el pensamiento darwinista no tuvo una acogida favorable entre la mayor parte de los pensadores que, por aquel entonces, construían los cimientos de las disciplinas sociales. Las afinidades electivas que las ideas evolucionistas desplegaron con el darwinismo social spenceriano, con los movimientos eugenésicos y con los ideales del etnocentrismo occidental (victoriano y germano principalmente) fueron razón suficiente para que muchos desestimaran la toma en consideración de la naturaleza humana como parte de la ciencia social. Además, las ciencias sociales se vieron en la necesidad de definir un espacio propio en el que crecer e instalarse, a salvo de las amenazas que otras disciplinas podían verter en contra de sus intereses. La combinación de estas circunstancias bloqueó eficazmente, la comunicación entre la biología evolutiva y las ciencias sociales. No es

${ }^{2}$ Esta argumentación la desarrolla en extenso en el capítulo 5 de The Descent of Man. 
de extrañar, por ello, que, al consolidarse la síntesis neodarwinista en los años cincuenta del siglo pasado, se respetara la autonomía de la cultura frente a la biología en un claro intento no sólo de evitar conflictos académicos, sino también de hacerse perdonar la utilización ideológica del darwinismo en apoyo del racismo biológico que latía en las ideas del nazismo alemán.

\section{La cultura en las tradiciones de pensamiento humanista y científico-social}

Pensar la cultura ha sido, desde un primer momento, una tarea central para la investigación social. Para muchos, la cultura se ha constituido en el objeto de estudio central de la Antropología (o Etnología, según tradiciones), al tiempo que se ha integrado, como parte esencial, de una u otra manera, en los modelos elaborados por varias tradiciones de pensamiento sociológico (Weber, Durkheim, Parsons). Y, sin embargo, aún hoy, la cultura sigue mostrándose como una realidad escurridiza.

A pesar de las reticencias que suscita, la definición propuesta de Edward B. Tylor (1871) constituye, todavía hoy, un buen referente para comprender de qué hablamos cuando pronunciamos el término «cultura»: Cultura o civilización, tomada en su amplio sentido etnográfico, es ese complejo de conocimientos, creencias, arte, moral, derecho, costumbres y cualesquiera otras aptitudes y hábitos que el hombre adquiere como miembro de la sociedad. Sin embargo, trabajos como el de A. L. Kroeber y C. Kluckhohn (1985), en el que los autores recogieron y analizaron más de un centenar de definiciones acerca de la cultura, o el más reciente de A. Kuper (2001), muestran, más bien, que en las ciencias sociales no se ha conseguido a establecer un modelo o representación unitario y comúnmente aceptado acerca de esa realidad que llamamos cultura. Dentro de las tradiciones de pensamiento científico-social, la palabra cultura es un término polisémico cuyos significados se desplazan desde el idealismo al materialismo y desde los dominios de lo imaginario a lo conductual, incluyendo los aspectos materiales de la vida humana y los marcos conceptuales propios de cada comunidad (incluida la científica). A todo lo cual hay que añadir las disputas que han pretendido extender o restringir el concepto de cultura incluyendo como parte esencial de él los elementos folk, o, por el contrario, reduciendo su campo a la cultura con mayúsculas, la del homme savant. 
Como sabemos gracias a la abundante etnografía acumulada durante cientos de años, y no menos a través de nuestra propia experiencia como nativos de alguna en particular, las culturas (todas, incluso las más antiguas y primitivas) se nos presentan como gigantescos y abigarrados agregados compuestos por repertorios de variada naturaleza y origen. El origen empírico de cada uno de estos repertorios, sensiblemente distintos de unas culturas a otras, es difícil de precisar, en ocasiones imposible, pues en su mayor parte pertenece a y procede de un background folk cuyos orígenes se pierden en la noche de los tiempos, fragmentado en innumerables narrativas, tantas veces parciales y contradictorias. Sin embargo, esta condición tan propia de las tradiciones culturales no ha impedido que la mirada del científico elabore algunas conjeturas y haga algunas precisiones generales acerca de él.

Sin duda, tal y como las ciencias sociales han procurado mostrar una y otra vez, la primera y más elemental afirmación acerca del origen de cualquier configuración cultural empírica es que ésta resulta inseparable de los avatares históricos y de la propia dinámica cultural de cada comunidad humana. O dicho de otro modo, que la descripción y explicación de la realidad cultural de cualquier comunidad remite siempre, en primera instancia, a su propia historia y, en ella, a interminables cadenas causales que vinculan unos elementos culturales con otros, como extraordinarias y abigarradas estructuras tridimensionales, densas, arracimadas y dotadas, siempre, de una dimensión temporal histórica. Este factum, que los fundadores de las disciplinas científico-sociales percibieron con tanta intensidad, llegó a convertirse, de la Ilustración en adelante, en el punto de partida de toda teorización social y crítica, rindiendo extraordinarios resultados en la constitución de los saberes históricos. Y ello no sólo por su productividad teórica — sin duda potencialmente inflacionaria—, sino por su vocación emancipadora frente a los prejuicios espiritualistas y antiilustrados, haciendo ver que la vida de los individuos y las comunidades humanas está atravesada, retenida o impelida, por ciertos hechos y procesos de naturaleza colectiva y que la configuración de las relaciones sociales es siempre un producto histórico y nunca el mero reflejo de la naturaleza, el destino o la voluntad de los dioses.

Llevando estas convicciones a sus últimas consecuencias, R. Lowie, uno de los discípulos más destacados de F. Boas, el padre de la antropología norteamericana, se expresaba en 1917 afirmando que la cultura es una realidad sui generis que sólo puede ser explicada en sus propios términos (Lowie, 1917). Y aña- 
día que esa tesis no era el resultado de creencias de corte místico o espiritualistas, sino del propio método científico, de tal suerte que el futuro de la etnología dependería enteramente de la asunción del principio Omnia Cultura ex Cultura. Durkheim, por su parte, había manifestado que las naturalezas individuales son simplemente el material indeterminado que los factores sociales modelan y transforman. Su contribución consiste exclusivamente en actitudes muy generales, en predisposiciones vagas, consecuentemente plástica ${ }^{3}$. Y también, refiriéndose a la necesidad de mantener el objeto de la sociología, el hecho social, a salvo de las ingerencias de otras disciplinas, alertaba de que cada vez que un fenómeno social es explicado directamente por un fenómeno psicológico, podemos estar seguros de que la explicación está equivocada ${ }^{4}$.

Sin embargo, para poder ir más allá de una mera descripción y reconstrucción histórica de los fenómenos culturales, las diferentes tradiciones que nutren el entramado teórico y metodológico de la investigación social han tratado de elaborar modelos explicativos más ambiciosos, capaces de dar cuenta de los procesos culturales a partir de otros fenómenos (no menos complejos, por cierto) tales como la estructura social de las comunidades humanas, su infraestructura económica, el entramado funcional que se atribuye a los distintos sistemas que componen la vida colectiva, las necesidades psicosociales del ser humano o el lenguaje y los sistemas simbólicos (en una enumeración elemental, sólo orientativa). En cada uno de estos modelos teóricos, la irrefrenable libido sciendi ha pujado por ofrecer una explicación fuerte de los fenómenos culturales, mostrando su dependencia y su vinculación causal con otras variables. Así, por ejemplo, el materialismo histórico intentó dar cuenta de los fenómenos culturales a partir de su dependencia (más o menos matizada) de la base o infraestructura económica (de los modos de producción históricamente realizados), y, por supuesto, de los tipos de relación social y dominación engendrados por ella, de suerte que una buena parte de eso que llamamos cultura adoptara la forma de una superestructura ideológica, más aparente que real (aunque no por ello carente de efectos performativos) a los efectos de la interpretación histórica del devenir de las sociedades humanas.

Las teorías sobre la cultura, cuyas manifestaciones más relevantes vamos a recorrer de forma sumaria, han acentuado, diferencialmente, aspectos muy dis-

3 Citado por S. Lukes en LuKES, S.: E. Durkheim: su vida y su obra, Siglo XXI, Madrid, 1984.

${ }^{4}$ Idem, LUKES, S., 1984. 
tintos. Por una parte, especialmente en los años 20 y 30 del pasado siglo, la cultura fue concebida como conducta aprendida, una definición nacida bajo el influjo del conductismo y de los estudios comparados del comportamiento animal, la incipiente etología. Sin embargo, la antropología norteamericana pronto hizo recaer la atención sobre otros aspectos. Bajo la poderosa influencia del particularismo, contrario al ímpetu evolucionista o al reduccionismo de corte científico, Krober y Kluckhohn (1952) definieron la cultura como formas de comportamiento, explícitas o implícitas, adquiridas y transmitidas mediante símbolos, singularizadoras de las comunidades humanas y plasmadas, en gran medida, en objetos. Según ellos, las culturas entrañan, detrás de los aspectos de comportamiento, sistemas de ideas y valores tradicionales, transmitidos de generación en generación, de suerte que si la acción puede ser considerada parte esencial de la cultura, no es menos cierto que ésta comprende también el sistema de restricciones y normas que dirigen y motivan la acción humana. La cultura posee, pues, diferentes niveles de concreción que incluyen la conducta aprendida, desde luego, pero también los valores y normas que la motivan, los discursos ideológicos legitimadores de esos valores y normas y, en último término, grandes principios generadores de orden y sentido, capaces de integrar áreas diferentes de experiencia.

Por otra parte, el rechazo a la especulación evolucionista de la literatura científica decimonónica, representado paradigmáticamente por F. Boas, acentuó la consideración de la cultura como una esfera singular, autorreferente, atada a los particularismos de la idiosincrasia y los avatares históricos de cada comunidad. Este impulso propició que buena parte de la investigación cultural se orientara a afinar, mediante una meticulosa etnografía altamente sensible a lo singular, la percepción de las diferencias interculturales. Como resultado de este trabajo, sostenido durante décadas, la cultura, cada cultura, adoptó la imagen de una totalidad, una gestalt o forma cultural específica y única.

En general, en la investigación antropológica (y social) predominó una visión que, si bien aceptaba que la cultura es un producto humano desarrollado a partir de la interacción entre el hombre y el medio, consideraba las gestalten o formas culturales como realidades autónomas, genuinos e irrepetibles productos de la historia: la cultura vendría a ser ese precipitado presente en las personas que configura su percepción de los acontecimientos, de otras personas y de la situación que los rodea de modos no determinados exclusivamente por la biología y 
la presión del medio. En expresión de Boas (1896), todo proceso cultural es un proceso histórico, un crecimiento integrado de elementos de la cultura, procedentes de diferentes fuentes, que se han unido en una configuración histórica.

Mientras tanto, por su parte, la antropología de raíces dukheimianas, representada por Radcliffe-Brown, el padre de la antropología social británica, prestó mayor atención a los vínculos entre estructura social y formas culturales, pero priorizando la dependencia de lo cultural respecto de lo social. En sus investigaciones, Radcliffe-Brown (1952) trató de abstraer las relaciones estructurales presentes en los fenómenos sociales e hizo ver cómo la investigación de los elementos culturales (religión, parentesco, derecho...), un programa tendente al idealismo dentro de la tradición norteamericana, ha de hacerse a la par que se investigan los principios estructurales que definen las relaciones sociales empíricas que tienen lugar en el seno de los grupos humanos, pues ambos fenómenos, cultura y estructura social, se encuentran causalmente vinculados y, hasta cierto punto, se expresan mutuamente.

Este sencillo bosquejo de la pluralidad de significados atribuidos a la cultura no podría finalizar sin considerar dos orientaciones sumamente influyentes. En primer lugar, aquellas teorizaciones que han destacado, por encima de cualquier otro aspecto, la dimensión simbólica de la cultura. Desde este punto de vista, el análisis de la realidad cultural debe partir de la dimensión significante que acompaña a todo fenómeno humano (conductual, material o imaginario), en virtud de la cual cada retablo cultural empírico, del más simple al más complejo, se convierte en un denso sistema semiótico y, en consecuencia, en un producto singular que reclama, del intérprete, una atenta descodificación. En segundo lugar, aquellos otros programas que, como reacción ante el idealismo, han intentado apartar la investigación antropológica del plano del significado, un territorio brumoso y confuso, orientando su trabajo hacia el descubrimiento de regularidades nomológicas transculturales, sustentadas sobre principios materialistas.

La consideración de la cultura como sistema de símbolos ha adoptado, al menos, tres formas básicas. De una parte, una visión formalista en la que los elementos culturales son tomados como signos dentro de sistemas semióticos completos. Así, el estructuralismo antropológico francés, personalizado en LeviStrauss, condujo el análisis de la cultura hacia un espacio teórico inexplorado hasta ese momento. Las culturas se presentan a los ojos del estructuralista como 
el resultado contingente de un sistema elemental de oposiciones binarias, una gramática profunda cuyas transformaciones, dentro de un campo combinatorio de posibilidades, dan lugar a las formas culturales empíricas, unidas, en lo más profundo, por su origen en las características de una mente universal (Levi-Strauss 1949, 1962).

Por otra parte, la naturaleza simbólica y comunicativa de la cultura ha sido explorada desde el estudio de las condiciones cognitivas que posibilitan su existencia y modulan sus contenidos, mostrando la existencia de patrones de variación cultural dirigidos y limitados por las condiciones internas de nuestra mente cultural (Goodenough, 1971; Lakoff y Johnson, 1980).

Por último, una hermenéutica de la cultura inspirada en la hermenéutica textual, que rechaza la búsqueda de regularidades simbólicas universales y que considera cada cultura como una realidad singular e irrepetible. Las culturas, en opinión de C. Geertz (1973), son patrones de significados transmitidos históricamente y materializados en formas simbólicas, mediante las cuales los hombres se comunican, perpetúan y desarrollan su conocimiento sobre la vida y sus actitudes hacia ella. Las culturas describen el mundo, inscribiendo en él sus significados, y mediante ellos dan sentido y limitan la acción. El análisis de la cultura, pues, no puede ser otra cosa que lectura, traducción e interpretación, búsqueda de significado.

Sólo a partir de los años cincuenta del pasado siglo consiguió hacerse paso una línea de investigación materialista, abiertamente enfrentada idealismo de la antropología norteamericana y de los excesos formalistas (o hermenéuticos) del modelo semiótico. Estos programas de perfil materialista han buscado la manera de vincular causalmente factores tales como la demografía, el marco geográfico, los recursos naturales (como la disposición de recursos energéticos) y la tecnología para descubrir y expresar regularidades nomológicas transculturales. Estos programas han retomado los objetivos de las teorías evolucionistas en orden a reconstruir los patrones de desarrollo histórico de las comunidades humanas, mostrando, en ellos, los vínculos entre condiciones ecológicas, sistemas de parentesco, actividad productiva y organización sociopolítica (White, 1949; Steward, 1955; Harris, 1982). Sin embargo, curiosamente, aún dentro de programas como el materialismo cultural, apartado de los presupuestos idealistas y holistas más ortodoxos, los principios darwinistas de una ciencia de la cultura no han tenido cabida, o incluso han sido abiertamente rechazados (Harris, 1982). 
¿Qué balance podemos hacer de este continuado y a la vez tan diverso esfuerzo intelectual por comprender la realidad cultural? Si exceptuamos el caso de B. Malinowski, más difícil de interpretar por su fuerte apuesta a favor de un funcionalismo psicosocial, las tradiciones que articulan el cuerpo central de teoría en las ciencias sociales, aunque dispares en muchos sentidos, han compartido la convicción de que las culturas constituyen totalidades que han de ser interpretadas sin referencia a las características psicobiológicas de la naturaleza humana (y a su historia filogénetica). La posición antropológica dominante en las ciencias sociales, si bien acepta que las aptitudes de los seres humanos para la cultura son el resultado de la evolución de nuestro cerebro, mantiene que el aprendizaje social es una capacidad de carácter general, no específica, que permite a los individuos desenvolverse en cualquier cultura si son educados en ella desde niños. La cultura debe ser, por tanto, un campo de trabajo exclusivo de las ciencias sociales.

El desarrollo reciente de la investigación naturalista ha puesto sobre la mesa un abundante y rico material empírico y teórico que reclama una valoración atenta y fría de sus resultados. Existen poderosas razones para hacerlo, pero, finalmente, una por si sola ya es suficiente: las ciencias sociales necesitan pensar a fondo la naturaleza humana. Resulta indispensable liberar este concepto del papel subsidiario y maldito que ha desempeñado hasta hoy y reclamar una centralidad explícita que nunca se le ha concedido en este ámbito. Y ha de ser así porque las ciencias sociales no pueden construirse, ni construir sus objetos, sin hacerse cómplices de una visión del hombre.

Ciertamente, una representación biológica de la naturaleza humana, por adecuada y bien fundada que resulte, nunca podrá dar cuenta linealmente de la producción cultural humana o del origen y mantenimiento de las estructuras sociales. Como tampoco habrá de encontrar su función en la atribución de títulos de nobleza y legitimidad a los diferentes marcos morales o políticos, ni en erigirse en criterio para establecer estándares de normalidad y dignidad humanas - actitudes intelectuales de las que tenemos, desgraciadamente, sobradas pruebas. El servicio que la investigación naturalista puede proporcionar a las ciencias sociales es otro.

La necesidad de repensar asuntos tales como la naturaleza del vínculo social, la centralidad de las creencias en los fenómenos sociales, los procesos de sociali- 
zación y la naturaleza de la cultura, entre otros, pone en primer plano la oportunidad de mostrar hasta qué punto las investigaciones naturalistas pueden aportar luz al insustituible trabajo intelectual de las ciencias sociales (Castro et al. 2008). Sin embargo, en contra de la opinión más extendida, esta nueva luz no consiste tanto en la identificación de las bases psicobiológicas de la conducta humana (y, en consecuencia, de la cultura), un camino legítimo y muy necesario, cuanto en promover la modificación del núcleo duro del programa de investigación científico-social que ha dado en llamarse modelo estándar (ME) (Cosmides y Tooby, 1992), procurando el abandono de ciertos tópicos y convicciones que las ciencias sociales, bajo diferentes tradiciones, han mantenido vivos desde su origen. Además, incorporar un modelo biológico de la naturaleza humana nos debería permitir la obtención de ciertas reglas heurísticas capaces de redirigir la investigación empírica y abrir nuevos senderos de trabajo. Una tarea que, sin embargo, en nada supone una merma para la legitimidad de la investigación social, ni para el ejercicio de sus capacidades teóricas e investigadoras.

\section{La cultura como objeto de investigación naturalista}

La necesidad de analizar la conducta humana asumiendo, con todas sus consecuencias, el origen evolutivo de nuestra especie seguía latente y sin resolver a mediados de los años 70 del siglo pasado, ya bien consolidada la síntesis neodarwinista. Por ello, no es de extrañar que en estas últimas décadas hayan surgido distintas aplicaciones de la teoría evolutiva, especialmente la sociobiología, la ecología del comportamiento, la memética, la psicología evolucionista y las teorías coevolutivas de la herencia dual, que han puesto el énfasis en el estudio de la cultura y de la conducta humana desde una perspectiva darwinista, en un intento de explicar qué conductas, creencias y valores se extienden en las sociedades humanas.

Se ha recuperado así el viejo proyecto de Darwin de desarrollar una ciencia de la naturaleza humana. Dicho proyecto pretende dar cuenta de los orígenes de nuestras aptitudes para la cultura y de la propia naturaleza de los procesos culturales desde los principios de la biología evolutiva y de otras ciencias afines, que tampoco han escapado al influjo darwinista. Durante este tiempo, los programas de investigación implementados desde la sociobiología, la psicología evolucionista y las teorías de la coevolución gen-cultura han abordado el estudio de las 
culturas dispuestos a demostrar que éstas no pueden ser consideradas como sistemas autógenos y autorreferentes. Este propósito, en sí mismo, no es ajeno a la propia investigación social, preocupada por encontrar en las estructuras sociales, los sistemas semióticos y las fuerzas económicas, las variables rectoras del cambio cultural. Las diferencias, sin embargo, se hacen visibles inmediatamente que la investigación naturalista incorpora al explanans de los fenómenos culturales elementos procedentes de la constitución psicobiológica y la historia filogenética de nuestra especie, poniendo en relación los contenidos y procesos socioculturales con el ajuste local de nuestra arquitectura cognitiva, a través del cual tales disposiciones psicobiológicas se desenvuelven.

En el interior de los programas de investigación naturalista, la palabra cultura adopta un significado análogo, en su amplitud, al propuesto por Tylor, aunque interpretado con algunas particularidades: los contenidos culturales se conceptualizan como unidades de información transmisible, discretas y vinculadas con conductas (más que con la dimensión imaginaria o simbólica). La cultura es considerada como un enorme almacén de conocimiento e información que, en cada contexto local y para cada población particular, se encuentra disponible, al menos parcialmente, para sus miembros. Además, en las teorías de convolución gen-cultura, los contenidos culturales suelen ser considerados como unidades de contenido o rasgos conductuales sujetos a transmisión, en virtud de la fructífera analogía que esta conceptualización permite establecer entre las unidades de transmisión cultural y las unidades de transmisión genética.

El papel de la cultura en la ontogenia - y en lo que los científicos sociales denominan socialización y enculturación - es indiscutible. Mediante la estimulación que procede del medio social y a través de los aprendizajes que tienen lugar en él —entre otros factores—, madura y se configura el sistema nervioso de cada individuo, forjando una realidad personal, una identidad socialmente reconocible y competente, en la que se encuentran fundidas, indistinguibles realmente, las estructuras neurológicas y cualesquiera otras (pre)disposiciones innatas con los procesos madurativos socialmente estimulados y mediados. Tales procesos madurativos, alimentados por intensas experiencias de aprendizaje social, confieren al individuo las herramientas cognitivas y emocionales necesarias para el mantenimiento de la vida y lo preparan para una actuación comunicativa y un intercambio social adaptados a su entorno. 
La seguridad cognitiva y emocional que caracteriza el modo en que aprehendemos nuestra realidad inmediata y que se expresa tanto en nuestra adhesión a múltiples creencias, prácticas y valores, como en nuestro rechazo a otras formas empíricas de comportamiento, criterio y creencia — que se han forjado, eso sí, del mismo modo que las nuestra-, descansa en la fuerza configuradora de estos procesos de aprendizaje y maduración, en nuestra plasticidad natural y en el extraordinario peso de la experiencia. Las fenomenologías filosófica (Husserl), psicológica (Merlau-Ponty) y sociológica (A. Schutz, P. Berger, T. S. Lukmann) han retratado con extraordinaria precisión y riqueza, aunque desde posiciones teóricas cargadas de idealismo, la vivacidad, auntenticidad y seguridad cognitiva que caracterizan el mundo-de-la-vida y al particular modo humano de ser-enel-mundo, nuestra experiencia de sentirlo propio y verdadero. Ortega trataba las creencias, precisamente, como aquello que constituye y arma la sustancia eidética y vivencial de nuestro mundo, y no como a un mero contenido de nuestra mente: las ideas se tienen, en las creencias se está.

Desde un punto de vista naturalista, sin necesidad de negar en absoluto lo afirmado a propósito de las dimensiones históricas y locales de cualquier fenómeno cultural, los contenidos que componen el entramado de la cultura pueden distribuirse de acuerdo con una tripartición que, aunque insuficiente e imprecisa, puede resultar iluminadora. Por una parte, encontramos patrones de organización social, explotación de recursos, producción económica y creencias, estrechamente vinculados con las condiciones ecológicas que rodean al grupo humano en cuestión, tales como la proporcionalidad entre la tasa de energía disponible por individuo y las formas de vida establecidas en una colectividad. Forman parte de este primer grupo aquellas estrategias de comportamiento que son el resultado de cálculos racionales e instrumentales promovidos por un cerebro maximizador, diseñado por la selección natural para ese propósito, aunque tal afirmación no comprometa el modo en que ha de interpretarse el comportamiento humano general, irreductible a la lógica instrumental cuando se considera en conjunto.

Por otra parte, en la cultura es posible rastrear también la presencia de nuestras ancestrales disposiciones psicobiológicas, esas que biólogo E. Mayr llamaba causas últimas de nuestro comportamiento y que, tantas veces, nos empujan al margen o en contra de cualquier cálculo o estimación racional de riesgos o intereses. Estas disposiciones, mediadas siempre culturalmente, se manifiestan en 
asuntos muy diversos que atañen a aspectos tales como la alimentación, la conducta sexual, la cooperación, la formación de identidades, el sentimiento de pertenencia étnica, el emparejamiento, la agresividad, la modulación de las respuestas emocionales o, incluso, la habilidad para el razonamiento.

Sin embargo, esta caracterización resultaría claramente insuficiente si no incorporara, como tercer elemento, una singularidad intrínseca a toda cultura humana que, en cierto modo, nos devuelve al insigth que hemos atribuido al proyecto de una ciencia de lo social nacida de los principios ilustrados, a saber, que toda cultura se presenta como el resultado de un excepcional proceso de acumulación y transmisión de información, verdaderamente hipertrófico, que combina contenidos adaptativos e instrumentales junto a otros neutros o netamente no adaptativos, viajando y transformándose, de generación en generación, por medio del aprendizaje social. La cultura se desenvuelve como un sistema de herencia en el que tan crucial parece ser el elemento disposicional de naturaleza psicobiológica - con una posible base genética - como la azarosa deriva cultural irreductible a los dictados de la selección natural y los imperativos de la adaptación. Este hecho exige un esfuerzo por entender cómo es posible que las gestalten culturales, que son el más natural y singular de los productos de nuestra particular constitución psicobiológica, se muestren, al mismo tiempo, como conjuntos irreductibles a la aplicación mecánica de los algoritmos adaptacionistas.

De las diferentes aproximaciones naturalistas, la psicología evolucionista, fundada por los psicólogos L. Cosmides y J. Tooby, y la teoría de la herencia dual de los antropólogos R. Boyd y P. Richerson, han sido, hasta el momento, las que han logrado modelos más consistentes en el análisis de estas cuestiones. En lo que sigue, vamos a revisar brevemente los elementos básicos de ambos programas que, aunque rivalizan, son en buena medida complementarios. En la parte final del artículo, presentamos una propuesta alternativa, pero también compatible con ambos, basada en lo que hemos denominado aprendizaje social assessor (Castro y Toro, 2004; Castro et al. 2008).

\section{Psicología evolucionista y transmisión cultural}

La psicología evolucionista parte del hecho de que la mente humana posee un diseño estructural y funcional, un conjunto de mecanismos neuropsicológicos, 
que han surgido durante el proceso de hominización como instrumento para dotarnos de respuestas adaptativas frente a problemas tales como la selección de pareja, la adquisición del lenguaje, las relaciones familiares o la cooperación (Cosmides y Tooby, 1988, 1992, 1994; Buss, 1994, 1995; Tooby y Cosmides, 2005). La hipótesis de la modularidad masiva defendida por estos autores afirma que nuestro cerebro se encuentra cargado con un número indeterminado pero muy amplio de algoritmos ligados a contenidos de experiencia (arquitectura de dominio específico), lo que permite que el funcionamiento de nuestra mente sea mucho más eficiente. Leda Cosmides y John Tooby, los fundadores de esta disciplina, defienden que dichos mecanismos psicológicos condicionan, en buena parte, el tipo de rasgos culturales que se manifiestan y se transmiten en las sociedades humanas. El objetivo científico central no consiste en explicar la diversidad cultural, sino en utilizarla como evidencia empírica que nos permita arrojar luz sobre qué clase de mecanismos cognitivos la han hecho posible. Los compromisos teóricos de este programa lo oponen frontalmente al ME (Modelo Estándar) dominante en las ciencias sociales (Cosmides y Tooby, 1988, 2005), según el cual los individuos se comportan como recipientes más o menos pasivos de la tradición cultural en la que se educan, de suerte que las acciones individuales, salvo las relacionadas con fines biológicos obvios, responden a motivaciones que se encuentran en la propia cultura. La idea de naturaleza humana que maneja este modelo estándar describe a los seres humanos, siguiendo los dictados de Locke, como una tabla rasa colonizada por las distintas tradiciones culturales en las que se hallan inmersos los individuos.

Los psicólogos evolucionistas abordan el debate sobre la cultura tratando de analizar aspectos tales como: ¿cuáles son los mecanismos psicobiológicos que hacen posible la cultura humana?, ¿cómo han surgido tales mecanismos a lo largo del proceso evolutivo que conduce hasta nosotros?, ¿cómo reinterpretar la diversidad cultural desde una teoría unitaria y fuerte de la naturaleza humana? Comprender la cultura es, ante todo, comprender las estructuras cognitivas que la hacen posible y comprender, asimismo, cómo estas estructuras de la mente humana, surgidas en el Pleistoceno, pueden dar lugar a formas variables de expresión fenotípica cuando son situadas en ambientes diferentes. Si de verdad se desea comprender la estructura profunda de nuestras culturas, esa que subyace a la diversidad cultural, entonces debemos contemplar la cultura como el resultado variable y flexible de la interacción entre nuestra arquitectura mental y los ambientes en que nuestra especie se ha establecido. 
Frente a la visión del ME, Cosmides y Tooby defienden que los mecanismos psicobiológicos condicionan, en buena parte, el tipo de rasgos culturales que se manifiestan y se transmiten en los grupos humanos. La homogeneidad dentro de grupo, ese aire de familia tan perceptible cuando observamos la vida cotidiana de una comunidad humana local, debe ser interpretada como el resultado de la interacción entre la poderosa arquitectura modular de dominio específico de nuestras mentes y las condiciones ambientales en que ese grupo humano se ha desarrollado. Este conjunto de mecanismos forman una estructura altamente sensible a las condiciones iniciales, muy plástica y abierta — aunque no en el sentido que el ME atribuía a esta flexibilidad. Por ello, pueden dar lugar, de facto, a una inagotable variedad de formas culturales que, sin embargo, manifiestan, al mismo tiempo, una unidad profunda. Por la misma razón, la variación de las condiciones iniciales de tipo ambiental generará diferencias importantes, y aún crecientes, entre grupos dispersos y aislados. El error del ME, en este punto, se debe a la pertinaz creencia de muchos científicos sociales y humanistas en que la acción de los genes y de su expresión en la arquitectura de nuestra mente no puede traducirse en otra cosa que en rígidos patrones de conducta y que, en consecuencia, la flexibilidad fenotípica es incompatible con la presencia activa de estos mecanismos psicobiológicos.

Para afinar sus análisis, los psicólogos evolucionistas han propuesto la distinción entre cultura evocada y cultura adoptada o epidemiológica. La cultura adoptada consiste en un conjunto de creencias, valores, normas, tecnologías, etc., que fluyen de individuo a individuo a través del aprendizaje social (observación, imitación, enseñanza). Por su parte, la cultura evocada se compone del conjunto de variantes conductuales que son el resultado de la acción de los mecanismos psicobiológicos en cada contexto ambiental concreto. De acuerdo con el punto de vista de los psicólogos evolucionistas, buena parte de las diferencias culturales que se aprecian entre distintas poblaciones están producidas por el efecto singularizador del ambiente sobre la acción de la arquitectura de nuestra mente y, en consecuencia, son diferencias originadas dentro del marco de la cultura evocada. En tales casos, sería un error atribuir a la transmisión cultural el origen de una buena parte de la diversidad entre poblaciones, práctica ésta muy habitual dentro del marco del ME. Otro tanto puede decirse, en consecuencia, de la homogeneidad dentro de grupo. Ésta se ha interpretado tradicionalmente como el efecto del fluir interno de unos mismos aprendizajes dirigidos por los principios de la transmisión cultural y el aprendizaje social. Sin embargo, la homogeneidad 
intrapoblacional debe ser explicada como el resultado del trabajo de la arquitectura cognitiva y emocional de nuestra especie cuando se despliega y madura en contextos ambientales similares y bajo los efectos de ciertas regularidades poblacionales. Esta misma tesis cobra valor explicativo cada vez que se encuentra evidencia empírica que vincula las formas culturales básicas de grupos poblacionales aislados entre sí, pero situados en ambientes con características similares.

Cosmides y Tooby interpretan el concepto de cultura adoptada como un conjunto de fenómenos restringido a representaciones y fenómenos reguladores que existen, al menos, en una mente individual y que pueden pasar a otras mentes por medio de la observación e interacción entre el individuo fuente y el observador. Tal flujo es posible gracias a ciertos mecanismos de inferencia, por medio de los cuales el observador recrea las representaciones o elementos reguladores presentes en la mente del otro. Los autores expresamente evitan usar la fórmula cultura transmitida, pues el término transmisión, referido a los procesos de flujo de representaciones, parece poner el acento en los individuos que realizan el intercambio, en sus interacciones e intenciones, cuando lo correcto, desde la perspectiva de la psicología evolucionista, es adoptar el punto de vista de la arquitectura de nuestra mente y de sus mecanismos modulares. Para ellos, una buena parte de las cosas que se transmiten culturalmente no se transmiten realmente, sino que son inferidas por los individuos a partir de sus observaciones del mundo y de las conductas de otros individuos. De acuerdo con esta hipótesis, la cultura, más que una realidad autónoma constituida por significados objetivos y externos a los individuos, una esfera independiente dotada de una lógica y una mecánica propias, se muestra como un mundo de representaciones. Éstas existen, sensu estricto, en las mentes de los individuos (y, por supuesto, en infinidad de representaciones públicas externas a la mente de los individuos, pero que lo son en tanto que éstos pueden atribuirles una significación) y se presentan dotadas de una notable estabilidad y consistencia a consecuencia del modo en que las mentes operan sobre ellas, poniendo en juego los mismos mecanismos y algoritmos cognitivos y emocionales.

Desde una postura marcadamente cognitivista, que enlaza plenamente con los trabajos del antropólogo D. Sperber (1996), Cosmides y Tooby intentan mostrar que la arquitectura cognitiva de nuestra mente tiene un efecto selectivo sobre las representaciones, favoreciendo unas y penalizando otras. La dinámica cultural se contempla como un fenómeno epidemiológico, es decir, como una diná- 
mica de las representaciones que se encentra en constante flujo dentro de una población determinada y a lo largo del tiempo. La cultura y la arquitectura psicológica de nuestra especie se hallan íntimamente vinculadas, por lo que jamás podrá tenerse una adecuada comprensión de los fenómenos culturales a partir del tratamiento de la cultura como una esfera independiente. Sin embargo, tan erróneo sería presentar lo cultural como una realidad externa al individuo, dotada de una dinámica propia y emancipada de él, como reducir lo cultural a lo puramente psicológico (a las representaciones y su mecánica). Existe una estrecha relación entre los fenómenos culturales y los fenómenos psicológicos, pero no una equivalencia directa, en el sentido de una reducción de lo cultural a lo psicológico, sino en tanto que los fenómenos culturales son los patrones ecológicos de los fenómenos psicológicos. Comprender la dinámica cultural, en consecuencia, es comprender los factores psicológicos y ambientales responsables del éxito diferencial de las distintas representaciones que compiten en el flujo cultural. Esta postura radical acerca del efecto y valor de la transmisión cultural le ha valido numerosas críticas a la psicología evolucionista.

\section{La teoría de la herencia dual: la cultura como sistema de herencia}

Frente a las tesis defendidas los psicólogos evolucionistas, Boyd y Richerson han acentuado el papel de la transmisión cultural en la cultura y el comportamiento humano. Para comprender adecuadamente la naturaleza de la cultura, como para comprender nuestra naturaleza cultural, debemos observar ésta, la cultura, como un sistema de herencia regulado por reglas análogas, pero no idénticas, a las que regulan la herencia biológica. La tesis central de los modelos de coevolución consiste en afirmar que los principios darwinistas pueden ser aplicados al estudio de la cultura y sus procesos, sin que esto signifique que se pueda asimilar, sin más, la herencia genética y la herencia cultural, pues presentan propiedades dispares. Detengámonos en mostrar estas diferencias: a) cuando de procesos culturales se trata, no estamos restringidos a imitar o recibir enseñanza sólo de nuestros padres - como ocurriría en la herencia genética一, sino que podemos aprender de otros individuos miembros de la generación parental o de otra; b) dado que nuestra imitación y aprendizaje pueden orientarse dentro del espacio generacional en cualquier dirección y dada la rapidez con que este proceso opera, la transmisión de ciertos rasgos culturales puede ocurrir como la pro- 
pagación de un virus, mostrando patrones epidémicos en la población; c) Algunos de esos rasgos pueden presentar un sentido adaptativo claro, otros pueden resultar neutros para el individuo y. por último, otros pueden ser no adaptativos - como el consumo de drogas; d) la transmisión cultural, a diferencia de la transmisión genética, no se restringe a la concepción, sino que se extiende a lo largo de toda la vida del individuo; e) la cultura constituye un sistema en el que es habitual la herencia de caracteres adquiridos.

Sin embargo, a pesar de estas diferencias, la transmisión cultural puede ser modelada de acuerdo con los principios darwinistas. En sus trabajos, iniciados a finales de los años setenta y recogidos, en 1985, en un texto programático titulado Culture and the Evolutionary Process, Boyd y Richerson han desarrollado un controvertido programa de investigación que intenta considerar seriamente las interacciones entre nuestra naturaleza biológica, nuestros genes si se prefiere, y las formas culturales. Instalados en tierra de nadie, estos investigadores han recibido numerosas críticas procedentes tanto del campo de la psicología evolucionista como de la antropología cultural. Los primeros han visto en sus trabajos una puerta abierta a los excesos especulativos de las ciencias sociales, la coartada naturalista que los estudiosos de la cultura necesitaban para blanquear sus categorías holísticas y darles carta de naturaleza científica. Los antropólogos culturales, por su parte, no han dejado de recelar de ellos, seguros de que, de una o de otra manera, la cultura terminaría sucumbiendo ante el determinismo genético. No obstante, más allá de los ajustes de cuentas entre escuelas y academias, existen poderosas razones para considerar seriamente sus conclusiones. Tomar la cultura como una parte de nuestra biología, un compromiso central para cualquier programa naturalista, es algo compatible con percibir la imposibilidad de explicar un fenómeno cultural como producto de la sola interacción entre nuestra arquitectura mental y las características del medio. Cualquiera que se acerque al estudio de los fenómenos culturales sabe que, en esa explicación, es necesario considerar otro factor determinante: el pasado cultural de cada población humana concreta. Sin él, la diversidad de las tradiciones culturales parecería arbitraria y quedaría convertida en un molesto residuo para la explicación científica. Explicar la cultura significa, por tanto, dar cuenta de cómo ésta ha llegado, en sí misma, a constituir un factor determinante en la génesis de nuestra propia naturaleza biológica y cómo, en consecuencia, ha adquirido, por su propia dinámica y condición, un indispensable papel explicativo en los asuntos humanos. 
Boyd y Richerson han hecho de esta tesis un objetivo central de su programa. Ahora bien, este objetivo ha de abordarse de manera sutil. Ciertamente, si la cultura existe y es producto de nuestra biología y si, como parece, nuestro cerebro es una fábrica de cultura y de intercambio cultural, es porque la cultura ha resultado ser una estrategia adaptativa muy exitosa. Esto es innegable. Sin embargo, al reconstruir el proceso evolutivo de nuestro cerebro y de su productividad cultural no podemos caer en una visión unilateral que circule desde nuestra constitución biológica hacia la cultura por una senda que trate de explicar todo en clave adaptativa, pues en ese caso una parte muy importante de la diversidad cultural se nos presentará como un incómodo repertorio de incomprensibles y caprichosos comportamientos y creencias, muchos enteramente inconsistentes con la acción de la selección natural. En consecuencia, lo correcto, en opinión de Boyd y Richerson, es renunciar a ver nuestra condición biológica como un conjunto de restricciones para nuestra vida cultural y optar por interpretar las relaciones entre la cultura y nuestra naturaleza psicobiológica como un complejo entramado de relaciones causales de ida y vuelta, que actúa en ambas direcciones. De este modo se podrá evitar la aparente necesidad de echar mano de lo cultural como realidad superorgánica, en tanto que única explicación plausible para una cultura irreductible a y contradictoria con los imperativos darwinistas.

La teoría de la herencia dual de Boyd y Richerson considera la evolución cultural de manera similar a como se concibe la evolución orgánica, es decir, como un cambio en la composición cultural de una sociedad, esto es, en el conjunto de rasgos culturales que presenta — memes, en la terminología que sugirió Richard Dawkins. Su modelo de partida recoge las tesis básicas del ME de las ciencias sociales: en cada nueva generación los individuos escogen un modelo cultural de la generación previa, ya sean sus padres o individuos elegidos al azar, y adoptan su conducta, de manera que las frecuencias de los distintos memes presentes en la población no varían. Es decir, la cultura replica la estructura fenotípica de la generación parental y se comporta como un verdadero sistema de herencia. Definen las fuerzas de evolución cultural como aquellas que son capaces de alterar las frecuencias de los memes a través de las generaciones. Los errores en la imitación, las migraciones, la deriva cultural y determinados procesos selectivos que condicionan la probabilidad de llegar a ser modelos culturales constituyen, en el ámbito cultural, fenómenos equiparables a los procesos de mutación, migración, deriva genética y selección natural, característicos de la evolución genética. Sin embargo, hay otros procesos que son exclusivos de la evolución cultural como la 
capacidad de modificar intencionalmente la conducta en búsqueda de nuevas y mejores soluciones a los problemas que deben afrontar los individuos, la herencia a la manera lamarckiana de esos caracteres adquiridos o la imposición de determinados rasgos por parte de un grupo social a otro.

Para Boyd y Richerson, el sistema de herencia cultural es independiente del genético, pero al mismo tiempo está conectado con él por la existencia de predisposiciones psicobiológicas que inciden sobre la propagación o la desaparición de los diferentes caracteres culturales. De ahí el nombre de herencia dual con el que designan a su teoría. Su tesis defiende que la selección natural ha favorecido la aparición de mecanismos cognitivos que permiten a los individuos adoptar conductas adaptativas, imitando a otros miembros de su grupo social. La clave es que esta adopción de conductas se realiza sin necesidad de explorar una a una cuál es la mejor opción, evitando así los costes de una evaluación que puede ser laboriosa o implicar riesgos. Tales mecanismos dan lugar a dos tipos de sesgos en la transmisión de memes, unos dependientes del contenido de éstos y otros del contexto social. Los primeros promueven tendencias directas a favor de unos memes concretos en lugar de otros y están ligados a la presencia en nuestro cerebro de mecanismos cognitivos, similares a los que propugnan los psicólogos evolucionistas, capaces de establecer preferencias a favor de variantes concretas. Los segundos suscitan sesgos inducidos por la situación local y dependen de dispositivos psicológicos que explotan claves ligadas no al contenido de los rasgos culturales concretos, sino a su abundancia en la población o a determinadas características de los modelos que las exhiben, tales como su estatus o su prestigio social. Se habla así de la transmisión conformista de aquellas variantes más frecuentes en una población o de la imitación preferencial de aquellas variantes que presentan los individuos de mayor éxito. Boyd y Richerson argumentan que los sesgos innatos relativos al contenido trabajan en contra de la propagación de diferencias arbitrarias entre las sociedades humanas, mientras que los sesgos relativos al contexto social pueden en ocasiones generar tradiciones sin valor adaptativo o, incluso, negativas. Encuentran así un factor psicobiológico que justifica la importancia de los efectos históricos y contingentes en la evolución cultural de las sociedades humanas. Tratan, por tanto, de incorporar al modelo naturalista lo que la evidencia antropológica y sociológica ha establecido sólidamente: que las culturas muestran interminables repertorios de conductas establecidas que, sin embargo, parecen superfluas desde la perspectiva adaptacionista y para las que resultaría completamente artificioso buscar causas genéticas directas. Este 
fenómeno requiere una explicación alternativa en la que se reconozca, al mismo tiempo, el peso de la naturaleza humana, su fundamento último, y el azar histórico y local.

\section{Una propuesta alternativa: la transmisión cultural assessor ${ }^{5}$}

Ninguna de las teorías analizadas otorga importancia al hecho de que la transmisión cultural en nuestra especie tiene lugar entre seres morales, capaces de evaluar la conducta propia y ajena en términos de valor, esto es, de categorizarla como apropiada o inapropiada y de actuar en consecuencia. Los humanos somos sujetos activos en el momento de la transmisión cultural, pero dicho papel activo no sólo corresponde al individuo que aprende, que puede, como hemos señalado antes, preferir unas variantes en lugar de otras, sino también al individuo que actúa como modelo, que es capaz de incidir sobre qué conducta adoptarán otros individuos a través de la aprobación o la reprobación de la misma. En este artículo proponemos que la transmisión cultural humana depende de un sistema particular de aprendizaje social que desarrollaron nuestros antepasados homínidos, el aprendizaje social assessor, basado en la aprobación o reprobación parental de la conducta que aprenden los hijos. Sugerimos que los seres humanos han desarrollado evolutivamente mecanismos psicobiológicos que facilitan este aprendizaje assessor, haciéndonos emocionalmente receptivos a la aprobación y a la censura ajena, de manera que asociamos lo apropiado o inapropiado de una conducta con las emociones de agrado o desagrado que genera su aceptación o rechazo en el entorno social más íntimo de cada individuo (Castro y Toro, 2004; Castro et. al, 2008). Esta es la gran novedad del aprendizaje social humano frente al de otros primates.

El aprendizaje social sólo ha alcanzado un nivel importante en nuestra especie, donde la cultura se ha convertido en un sistema de transmisión acumulativo de gran valor adaptativo. No está claro cuál es el factor que ha permitido esta evolución en los humanos pero no en otras especies de primates. Boyd y Richerson (1996) sugieren que la evolución cultural acumulativa no está presente en

5 Una exposición detallada del mismo puede encontrarla el lector en el libro de L. Castro, L. Castro y M.A. Castro «¿Quién teme a la naturaleza humana? Homo suadens y el bienestar en la cultura» (Tecnos, 2008). 
chimpancés debido a que éstos poseen una capacidad de imitar mucho menos consistente que la humana. Sugieren que la clave consistió en una mejora cuantitativa de la capacidad de imitación, precedida del desarrollo de la capacidad para elaborar una teoría de la mente, gracias a la cual fueron capaces de percibir a sus coespecíficos como seres provistos de una mente similar a la suya, dotada de intencionalidad.

Nosotros proponemos que una teoría de la mente y una mayor eficacia en la imitación fueron condiciones necesarias pero no suficientes para la aparición de la transmisión cultural humana. Esta transformación requirió además que nuestros antepasados homínidos desarrollasen la capacidad conceptual de categorizar su propia conducta en términos de valor — positivo/negativo, favorable/desfavorable_-, gracias a lo cual pudieron aprobar o desaprobar la conducta que desarrollaban sus hijos (Castro y Toro, 1998, 2002; Castro et al., 2004). Esta capacidad de aprobar o desaprobar permite transmitir información sobre el valor de la conducta, condicionando la preferencia de los hijos por unas alternativas $u$ otras. Según nuestro modelo la adopción de una conducta aprendida puede ser definida como un proceso con tres etapas. Primera, descubrir y aprender a llevar a cabo una conducta; segunda, poner a prueba y evaluar la conducta aprendida; y tercera, rechazar o incorporar la conducta dentro del repertorio personal de cada individuo. Consideramos que el aprendizaje social por imitación representa un mecanismo para descubrir una conducta dada, pero no compromete la adopción final de la misma. Es decir, los imitadores humanos, al igual que otros primates, pueden aprender las conductas que observan pero después han de evaluarlas antes de decidir incorporarlas a su repertorio. Cuando un individuo pone a prueba una conducta obtiene un determinado grado de satisfacción o rechazo en función del cual la incorpora o la desecha. Además, al igual que hacen otros animales con capacidad de aprender, los seres humanos pueden rectificar una decisión de aceptación ya tomada si cambia la recompensa obtenida con el transcurso del tiempo.

Nuestra argumentación plantea que nuestros antepasados homínidos dotados de ambas capacidades, la de imitar y la de aprobar o reprobar la conducta, a los que denominamos individuos assessor u Homo suadens (del latín suadeo: aconsejar), generaron un sistema cultural de herencia en sentido estricto, ya que la aprobación/reprobación de la conducta contribuye a que los hijos reproduzcan la estructura fenotípica de la generación parental, aprovechando la experiencia 
paterna. El valor adaptativo de esta capacidad de aprobar o reprobar la conducta de los hijos proviene principalmente de que: a) permite la rápida categorización de las alternativas culturales como positivas o negativas favoreciendo su adopción o rechazo; de esta forma se evitan los costes de una evaluación lenta y laboriosa y se atenúan los costes asociados a la experimentación de conductas peligrosas, sustituyendo una señal del mundo exterior potencialmente peligrosa por una parental inofensiva que señala que tal conducta es errónea; b) incrementa la fidelidad de la transmisión cultural, algo esencial para desarrollar un sistema de herencia acumulativo como el humano, ya que cuando la réplica no es fiel el individuo es reprobado y empujado a intentarlo otra vez.

En realidad, la capacidad conceptual de categorizar la conducta propia y ajena permite a los seres humanos aprobar o reprobar no solo la conducta de sus hijos, sino también la de otros individuos (Castro et al., 2008). Nuestra tesis sugiere que durante la ontogenia la comunicación valorativa entre padres e hijos es sustituida por otra, también en clave valorativa, entre individuos de la misma generación. De este modo, extendemos el modelo de transmisión cultural assessor entre padres e hijos a otro más general en el cual la aprobación o reprobación de la conducta proviene además de otros individuos no necesariamente emparentados entre sí. Cada individuo posee un grupo social de referencia, formado por aquellas personas con las que interacciona de manera preferencial y ante cuya opinión se muestra especialmente sensible: familiares, amigos y colegas. Nuestra propuesta defiende que los humanos han desarrollado mecanismos psicológicos que nos han hecho receptivos primero a los consejos parentales y, después, a la opinión de los miembros de nuestro grupo social de referencia. La presión de selección que promovió estas nuevas interacciones valorativas está relacionada con la necesidad de mejorar la cooperación para beneficio mutuo, clave en el éxito adaptativo de nuestra especie. Para que la cooperación sea rentable puede resultar imprescindible el que los individuos se coordinen a la hora de actuar. Por ello, parece razonable asumir que pudo evolucionar una tendencia a aceptar las recomendaciones de aquellas personas con las que más estrechamente se relaciona cada individuo, favoreciendo la coordinación y, como consecuencia, la cooperación del grupo. Las consecuencias negativas que puede tener la censura social, sobre todo el ostracismo, el rechazo a que cooperen con uno, puede explicar la evolución en la naturaleza humana de esta predisposición psicobiológica a compartir los valores con el grupo social de referencia, lo que se traduce en una tendencia incuestionable a aceptar la influencia social. 
Según esto, el aprendizaje social humano estaría condicionado precisamente por la satisfacción emocional que los individuos experimentan cuando hacen aquello que aprenden que deben hacer, con independencia de cuál sea el contenido concreto de ese deber. En nuestra opinión, es esta circunstancia la que mejor explica, desde una perspectiva psicobiológica, el extraordinario poder de lo social para modelar el comportamiento humano que tanto ha fascinado, condicionado y confundido a las ciencias sociales.

\section{Bibliografía}

BOAS, F., 1896, Race, language and culture, New York: McMillan (1955).

Boyd, R., y Richerson, P.J., 1985, Culture and the Evolutionary Process, Chicago: The Chicago University Press.

- 1996, "Why culture is common but cultural evolution is rare?», Proceedings of the British Academy 88: 77-93.

CASTRO, L., y TORO, M.A., 1998, «The long and winding road to the ethical capacity», History and Philosophy of the Life Sciences 20: 77-92.

- 2002, "Cultural transmission and the capacity to approve or disapprove of offspring's behaviour", Journal of Memetics - Evolutionary Models of Information Transmission, 6.

- 2004, «The evolution of culture: from primate social learning to human culture», Proceedings of the National Academy of Sciences, USA 101: 10235-10240.

Castro, L., Medina, A. y Toro, M.A., 2004, «Hominid Cultural Transmission and the Evolution of Language», Biology and Philosophy 19: 721-737.

Castro, L., Castro Nogueira, L. y Castro Nogueira M.A. (2008), ¿Quién teme a la naturaleza humana? Homo suadens y el bienestar en la cultura: biología evolutiva, metafisica y ciencias sociales. Madrid: Tecnos.

Cosmides, L. y ToobY, J., 1992, «The Psychological Foundations of Culture», en J. BARKOW, L. Cosmides, Y J. TOOBY, The Adapted Mind: Evolutionary Psychology and the Generation of Culture. New York: Oxford University Press, pp. 19-136.

DurkheIm, E., Las reglas del método sociológico. Madrid: Akal, 1985.

- 2004, El suicidio, Madrid: Losada.

GeERTZ, C., 1973, The Interpretation of Cultures, New York: Basic Books. 
Goodenough, W. H., 1971, Culture, Language, and Society, Reading, Mass.: AddisonWesley Modular Publications, No. 7.

HARris, M., 1982, El materialismo cultural, Madrid, Alianza.

Kroeber, A. L. y Kluchohn, C., Culture: a Critical Review of Concepts and Definitions, Nueva York: Random House.

Kuper, A., Cultura, la versión de los antropólogos, Barcelona, Ed. Paidos, 2001.

Lakoff, G. y Johnson, M., 1980, Metaphors We Live By, Chicago: Chicago University Press.

LeVI-STrauss, C., 1949, Les estructures élémentaires de la parenté, Paris: Presses Universitaires de France.

- 1962, El pensamiento salvaje, Paris: Presses Universitaires de France.

LOwIE, R. H., Culture and ethnology, New York, McMurtrie, 1917.

LuKES, S.: E. Durkheim: su vida y su obra, Madrid, Siglo XXI, 1984.

Radcliffe-Brown, A. R., 1952, Structure and Function in Primitive Society: Essays and Addresses, London: Cohen and West.

Richerson, P. y Boyd, R., 2005, Not by Genes Alone: How Culture Transformed Human Evolution. Chicago: University of Chicago Press.

SPERBER, D., 1996, Explaining Culture: A Naturalistic Approach, Oxford: Blackwell Publishing.

STEWARD, J. H., Theory of Cultural Change: The Methodology of Multilinear Evolution, Urbana: University of Illinois Press, 1955.

Tooby, J. y Cosmides, L., 2005, «Conceptual Foundations of Evolutionary Psychology», en David M. Buss (Ed.) The Handbook of Evolutionary Psychology. New Jersey: Wiley, Hoboken.

Tylor, E. B., 1871, Primitive Culture: Researches into the Development of Mythology, Philosophy, Religion, Art, and Custom, Gloucester, Mass.: Smith.

White, L. A., 1949, The Science of Cultura: a Study of Man and Civilization, New York: Farrar, Straus.

Recibido: 10/09/2009

Revisado: 15/09/2009 
